\title{
Patterns of bone marrow aspiration confirmed hematological malignancies in Eritrean National Health Laboratory
}

\author{
Natnael Belai ${ }^{1 *}$ (D) Amon Solomon Ghebrenegus ${ }^{2}$, Amin Ata Alamin ${ }^{3}$, Ghirmay Embaye ${ }^{4}$ and \\ Amanuel Kidane Andegiorgish ${ }^{5}$
}

\begin{abstract}
Background: Even though the incidences of hematologic malignancies have received considerable attentions globally, there is paucity of information on patterns of hematologic malignancy in Eritrea. The study was conducted to determine the distribution of various hematologic malignancies among patients who have received bone marrow examination, in the Eritrean National Health Laboratory.

Methods: A retrospective descriptive study design was used to determine the patterns of Hematologic malignancies diagnosed at the Eritrean National Health Laboratory from October 2015 to July 2017.

Results: Out of 207 patients who did bone marrow aspiration 52 patients were hematologic malignancy cases. The male to female ratio was 1:1. The age of the patients ranged from 2 to 80 years. Of the 52 patients 19, were less than 20 years of age and the remaining 33 were 20 years and above. Acute leukemia was the most common hematologic malignancy in the study area. It affected 18 of the cases followed by chronic myelogenous leukemia, chronic lymphocytic leukemia, myelodysplastic syndromes, multiple myeloma, and myeloprofilerative neoplasms. The presenting signs and symptoms in their decreasing frequency were generalized body weakness/fatigue, splenomegaly, fever, anemia, and lymphadenopathy. More than two-third of the patients had total leukocyte count greater than 10,000/ $\mathrm{\mu l}$.
\end{abstract}

Conclusion: This study shows that hematologic malignancies are not uncommon in Eritrea.

Keywords: Hematologic malignancies, Bone marrow aspiration, Distribution, Eritrea

\section{Background}

Cancer is a group of diseases characterized by uncontrolled growth and spread abnormal cells [1]. Cancer is increasingly recognized as the critical public health problem in Africa. Despite the growing burden, cancer is receiving low attention by policy makers, especially in developing countries. This could be due to either limited resources, the burdens of communicable diseases and other pressing public health problems, or it may be due to lack of awareness about the magnitude and burden of the diseases both at the present and future [2]. Eritrea is a country in east Africa experiencing an annual increase in the incidence of cancer. The age standardized rate for all cancers in Eritrean

\footnotetext{
* Correspondence: desnat27@gmail.com

'Orotta National Medical Surgical Referral Teaching Hospital, Asmara, Eritrea Full list of author information is available at the end of the article
}

hospitals and Eritrean National Health Laboratory from 2000 to 2010 was 20.3 per 100,000 [3].

Hematologic malignancies (HM) are a group of cancers that arise from a malignant transformation of cells of the bone marrow or the lymphatic system [4]. According to the study by Ferlay J et al., 2014, HMs were estimated to represent about 6.5\% of all cancers worldwide in 2012 [5]. Different etiological factors are believed to contribute to the development of these HMs as their incidence varies with geography, age and race/ethnicity. Even though environmental exposure to chemicals (such as pesticides, benzene, smoking etc.), as well as ionizing radiation and infectious agents are believed to be the causes of those malignancies, their exact cause remains unclear [6, 7]. There has been a considerable rise in the occurrence of $\mathrm{HM}$ over the past decades. World health organization predicts the number of 
HM cases to increase by about $48 \%$ in less developed countries in 2030 when compared to 2012 [5].

HMs are major burdens to afflicted patients and their families psychologically, medically and financially. As to our knowledge, no study has investigated the distribution of HM in Eritrea. It also remains a mystery whether the pattern of these malignancies follows a similar course to those reported in other countries. The aim of this research is therefore to describe the pattern of bone marrow aspiration confirmed HM in Eritrea based on age, gender, most common presenting signs and symptoms and the pattern of the complete blood cell count.

\section{Methods}

\section{Study design}

A retrospective study design was used to analyse the data recorded in Eritrean National Health Laboratory (ENHL) from October 2015 to July 2017.

\section{Study population}

The study population comprises of all patients who underwent bone marrow aspiration in the ENHL during the study period. The ENHL is the only laboratory in Eritrea which is capable of carrying out such investigations. The study population includes patients that were referred from different health facilities across the country for analyses. All data from the registration book was checked. Age, gender, address and most common presenting symptoms or complaints and automated complete blood count of each patient were recorded.

\section{Procedure of bone marrow aspiration}

Patients who were clinically suspected of having HMs, visceral leishmaniasis and pancytopenia were further tested with bone marrow aspiration. Aspiration was drawn from the iliac bone and Wright and Giemsa staining was done to the drawn samples followed by microscopic examination by a licenced hemopathologist.

\section{Data analysis}

Data was entered in excel sheet. Tables were used for presentation of the data. Percentages of the various categories of HMs were presented. The relationship between various $\mathrm{HMs}$ and demographic variables were explored using percentages in tables.

\section{Ethical clearance}

Ethical approval was sought out from the Research Ethics and Protocol Review Committee of the Ministry of Health of Eritrea in Asmara, Eritrea. Approval letter to proceed was sent to the Office to the National Health Laboratory. All concerned personnel of the National Health Laboratory were briefed on the objectives of the study. Confidentiality was assured before the study and hence data use was permitted for study purpose only.

\section{Exclusion criteria}

Patients registration/files found with incomplete information on variables like gender, age, and diagnosis were not included in this study.

\section{Result}

A total of 207 patients had undergone bone marrow aspiration examination from October 2015to July 2017. Out of these patients, 52 were diagnosed with HM. The male to female ratio of $\mathrm{HM}$ was 1:1. (Table 1). Age distribution of study subjects ranged from 2 to 80 years. (Table 1) Acute leukaemia (AL) was the most prevalent HM in this study. It affected $18(34.6 \%)$ of the cases followed by chronic myeloid leukemia (CML) (28.8\%), chronic lymphocytic leukaemia (CLL) (23.1\%), myelodysplastic syndrome (MDS) (7.7\%), Multiple Myeloma (MM) (3.8\%), and myeloproliferative neoplasm (MPN) (1.9\%).

Patients also had different clinical presentations and were categorized as: Generalized body weakness (GBW)/fatigue; Splenomegaly; Fever; Anemia; Lymphadenopathy; Weight loss/ loss of appetite; Headache/light headedness/blurred vision/dizziness; Left upper quadrant (LUQ) pressure/distension; Bleeding diatheses; Shortness of breath (SOB)/ cough/respiratory distress; Hepatomegaly; Joint pain/swelling; and Others (sore throat, dyspepsia, diarrhea, vomiting, hypercalcemia, hypoalbuminemia).

Around one-fourth (26.7\%) of patients with CML and one-sixth (16.7\%) of CLL presented with LUQ pressure sensation or swelling. Around three-fourth $(74 \%)$ of the patients with CML also presented with splenomegaly followed by AL (39\%) and CLL (9\%). The patients with AL, CLL, CML and MDS presented with GBW or fatigue with 44.4, 41.7, 33.3 and $75 \%$ respectively. Hepatomegaly was present in $11 \%$ of the patients with AL and $13.3 \%$ of patients with CML. Lymphadenopathy was seen in $16.7 \%$ of patients with $\mathrm{AL}$ and $50 \%$ of patients with CLL. Patients with AL, CLL and CML presented with fever

Table 1 Distribution of HMs according to gender and age

\begin{tabular}{llllllllll}
\hline Type of HM & \multicolumn{3}{l}{ Gender } & & \multicolumn{5}{l}{ Age group (in years) } \\
\cline { 2 - 3 } \cline { 7 - 9 } & Male & Female & $0-20$ & & $21-40$ & $41-60$ & $61-80$ & Total \\
\hline AL & 10 & 8 & 14 & 3 & 1 & 0 & 18 \\
CLL & 7 & 5 & 1 & 0 & 6 & 5 & 12 \\
CML & 7 & 8 & 3 & 4 & 7 & 1 & 15 \\
MDS & 0 & 4 & 1 & 1 & 2 & 0 & 4 \\
MPN & 0 & 1 & 0 & 0 & 0 & 1 & 1 \\
MM & 2 & 0 & 0 & 0 & 1 & 1 & 2 \\
\hline
\end{tabular}

Abbreviation: HM hematologic malignancy, AL acute leukemia, CLL chronic lymphocytic leukaemia, CML chronic myeloid leukemia, MDS myelodysplastic syndrome, MM Multiple Myeloma, MPN myeloproliferative neoplasm 
Table 2 Distribution of Hematologic Malignancies by clinical presentation

\begin{tabular}{|c|c|c|c|c|c|c|c|}
\hline \multirow[t]{2}{*}{ Variables } & \multicolumn{6}{|c|}{ Hematologic Malignancies [Number] } & \multirow[t]{2}{*}{ Total } \\
\hline & $\overline{A L}$ & CLL & CML & MDS & MPN & $\mathrm{MM}$ & \\
\hline GBW/fatigue & 8 & 5 & 5 & 3 & 0 & 0 & 21 \\
\hline Splenomegaly & 7 & 1 & 11 & 0 & 0 & 0 & 19 \\
\hline Fever & 8 & 5 & 4 & 0 & 0 & 0 & 17 \\
\hline Anemia & 5 & 2 & 1 & 1 & 0 & 1 & 10 \\
\hline Lymphadenopathy & 3 & 6 & 0 & 0 & 0 & 0 & 9 \\
\hline Weight Loss & 1 & 3 & 3 & 0 & 0 & 0 & 7 \\
\hline Headache & 3 & 1 & 3 & 0 & 0 & 0 & 7 \\
\hline Bleeding diathesis & 4 & 0 & 1 & 1 & 0 & 0 & 6 \\
\hline LUQ distention & 0 & 2 & 4 & 0 & 0 & 0 & 6 \\
\hline Shortness of breath & 4 & 0 & 0 & 1 & 0 & 0 & 5 \\
\hline Hepatomegaly & 2 & 0 & 2 & 0 & 0 & 0 & 4 \\
\hline Joint pain & 3 & 0 & 0 & 0 & 0 & 0 & 3 \\
\hline
\end{tabular}

Abbreviation: GBW Generalized Body Weakness, LUQ Left Upper Quadrant

44.4, 41.7 and $26.7 \%$ respectively. Anemia was common to all HM except for MPN (Table 2).

Forty-eight (92.3\%) of the 52 patients who underwent bone marrow aspiration had results of complete blood cell count. Out of these 33 had total WBC count greater than 10,000/ $\mu$ l. 42 had hemoglobin level less than $12 \mathrm{~g} / \mathrm{dl} .28$ had MCV between 85 and $100 \mathrm{fL}$ and 13 had MCV greater than $100 \mathrm{fL}$. 29 of the patients had platelet count less than $150,000 / \mu \mathrm{l}$ and about 5 had platelet counts greater than $450,000 / \mu \mathrm{l}$ (Table 3).

\section{Discussion}

To our knowledge this is the first study in Eritrea that describes the pattern and distribution of HM in terms of age, gender, common clinical presentation and the pattern of the CBC.
AL was the most common HM and accounted for 18 of the $52 \mathrm{HMs}$, whereas CML and CLL were the second and third most recurring HMs, accounting for 15 and 12 of the cases respectively. This was consistent with the findings of studies from Bangladesh and Iran [8,9]. Studies carried out in Yemen and Nigeria reported AL to be the third most common HM [10, 11]. Studies in Eastern Morocco, Egypt, South Africa, Yemen and Nigeria all conclude as NHL as their most common HM. Other than the South African study, all the above mentioned studies also report $\mathrm{HL}$ as their second most recurring HM [8, 10-13].

Of the 52 cases, HMs were most commonly diagnosed in ages less than 20 years, with 19 cases, followed by the 40-60 age group. Similarly, ALs were more common in the age group-under 20 years making up 14 of the patients, while CML was found most common in patients over 20 years (12), followed by CLL (11), MDS (3), MM (2) and MPN (1). Compared to the previous studies, the findings of the present study were found to be inconsistent. For example, Eastern Morocco reported that the most common HM in patients less than 20 years of age were the lymphomas [10]. The study also reported that the most HMs were diagnosed in patients aged greater than 60 years [10]. Hossain et al. also had similar findings [11]. We suspect that this may be due to our inability to include the lymphomas in this study.

The presenting signs and symptoms of the present study in their descending percent were GBW/fatigue; Splenomegaly; Fever; anemia; Lymphadenopathy; Weight loss/ loss of appetite; Headache/light headedness/blurred vision/dizziness. This was in line to the findings of studies done by Prajapati et al., Weldetsadik AT, Das et al. and Siddaiahgari et al. [14-17]. Majority (42) of the patients with $\mathrm{HM}$ were found to be anemic in our study.

In the present study the male to female ratio was 1:1. Many studies carried out in the Middle East, Asia, Africa

Table 3 Distribution of HM according to Complete Blood Count

\begin{tabular}{|c|c|c|c|c|c|c|c|c|}
\hline \multirow[t]{2}{*}{ Variable } & \multirow[t]{2}{*}{ Value } & \multicolumn{6}{|c|}{ Hematologic Malignancies [Number] } & \multirow[t]{2}{*}{ Total [Number] } \\
\hline & & $\overline{\mathrm{AL}}$ & CLL & CML & MDS & MPN & MM & \\
\hline \multirow[t]{2}{*}{$\overline{W B C}\left(\times 10^{3} / \mu \mathrm{l}\right)$} & $>10$ & 8 & 11 & 14 & 0 & 0 & 0 & 33 \\
\hline & $<10$ & 8 & 1 & 0 & 4 & 1 & 1 & 15 \\
\hline \multirow[t]{2}{*}{$\mathrm{HGB}(\mathrm{g} / \mathrm{dl})$} & $<12$ & 16 & 8 & 13 & 4 & 0 & 1 & 42 \\
\hline & $>12$ & 0 & 4 & 1 & 0 & 1 & 0 & 6 \\
\hline \multirow[t]{3}{*}{$\mathrm{MCV}^{\mathrm{a}}(\mathrm{fL})$} & $>100$ & 4 & 4 & 4 & 0 & 1 & 0 & 13 \\
\hline & $85-100$ & 9 & 7 & 8 & 3 & 0 & 1 & 28 \\
\hline & $<85$ & 3 & 1 & 2 & 0 & 0 & 0 & 6 \\
\hline \multirow{3}{*}{$\begin{array}{l}\text { PLT } \\
\left(\times 10^{3} / \mu l\right)\end{array}$} & $>450$ & 0 & 0 & 4 & 0 & 1 & 0 & 5 \\
\hline & $150-450$ & 0 & 4 & 8 & 1 & 0 & 1 & 14 \\
\hline & $<150$ & 16 & 8 & 2 & 3 & 0 & 0 & 29 \\
\hline
\end{tabular}


and the UK reported a male predominance in HMs ranging from 1.1 (Eastern Morocco) to 2.2 (Bangladesh) [8$12,18,19]$.

The study has a number of limitations. As there is no functioning histopathology unit in Eritrea, we were forced to exclude HMs that require tissue biopsy like lymphomas and only analyzed patients who underwent bone marrow aspiration to confirm the HMs. The other limitation is the nature of the study. As it is retrospective data analysis, many of the results had not distinguished ALL from AML, labeling them both as AL. Therefore, we had to combine ALL and AML to AL. The morphological analysis of the samples and the absence of detailed studies like flow cytometry or cytogenetic studies along with the small sample size are also important limitations of the study.

\section{Conclusion}

This study elaborates that HMs are present in Eritrea. This study was the very first step in understanding the patterns and distribution of these diseases. Further inquiries are needed to clearly establish the epidemiology, potential risk factors, biology and genetics of HMs in Eritrea. Moreover, physicians should be aware that peripheral blood smears could also be used to increase suspicion of the disease.

\section{Abbreviations}

AL: Acute leukemia; ALL: Acute lymphoblastic leukemia; AML: Acute myeloid leukemia; CLL: Chronic lymphocytic leukemia; ENHL: Eritrean National Health Laboratory; GBW: Generalized Body weakness; HGB: Hemoglobin;

HL: Hodgkin's lymphoma; HM: Hematological malignancies or Hematological malignancy; LUQ: Left upper quadrant; MCV: Mean cell volume;

MDS: Myelodysplastic syndromes; MM: Multiple myeloma;

MPN: myeloprofilerative neoplasms; NHL: Non-Hodgkin's lymphoma;

PLT: Platelets; SOB: Shortness of breath; WBC: White blood cells

\section{Acknowledgments}

We acknowledge all the members of ministry of health for their support in conducting this research.

\section{Funding}

Not applicable.

\section{Availability of data and materials}

The data of this study are available from the corresponding author on reasonable request.

\section{Authors' contributions}

NB conceived and wrote the proposal. ASG and AA strengthened it. AA in collaboration with GE analyzed and interpreted the samples. Data was entered by GE and AKA did the analysis. NB and ASG wrote the initial draft and edited finally by the rest of the authors. All the authors read and approved the final draft.

\section{Ethics approval and consent to participate}

Ethical approval was sought out from the Research Ethics and Protocol Review Committee of the Ministry of Health of Eritrea in Asmara, Eritrea. Due to retrospective nature of the study, informed consent was waived by Health Research Protocol Review and Ethical Committee of the Ministry of Health of Eritrea with the reference number of 01/082017. Confidentiality was assured before the study and hence data use was permitted for study purpose only.
Consent for publication

Not applicable.

\section{Competing interests}

The authors declare that they have no competing interests.

\section{Publisher's Note}

Springer Nature remains neutral with regard to jurisdictional claims in published maps and institutional affiliations.

\section{Author details}

${ }^{1}$ Orotta National Medical Surgical Referral Teaching Hospital, Asmara, Eritrea. ${ }^{2}$ Ghindae Zonal Referral Hospital, Ghindae, Eritrea. ${ }^{3}$ Department of Pathology, University of taif, Taif, Saudi Arabia. ${ }^{4}$ National Health Laboratory, Asmara, Eritrea. ${ }^{5}$ Asmara Collage of Health Science, Asmara, Eritrea.

Received: 28 August 2018 Accepted: 5 April 2019

Published online: 02 May 2019

References

1. American Cancer Society. Cancer Facts \& Figures 2014. Atlanta: American Cancer Society; 2014.

2. American Cancer Society. Cancer in Africa. Atlanta: American Cancer Society; 2011.

3. Adom H, Tesfamichael D, Weldu H, Hailemichael M, Eman D, Mehari T, Semere G, Fadlelmola F. Trends in the incidence of Cancer in Eritrean hospitals and Eritrean National Health Laboratory 2000-2010. UKJPB. 2016;4(5):47-55.

4. Flowers CR, Glover R, Lonial S, Brawley OW. Racial differences in the incidence and outcomes for patients with hematological malignancies. Curr Probl Cancer. 2007:31(3):182-201.

5. Ferlay J, Soerjomataram I, Dikshit R, Eser S, Mathers C, Rebelo M, et al. Cancer incidence and mortality worldwide: sources, methods and major patterns in GLOBOCAN 2012. Int J Cancer. 2014;136(5):E359-86.

6. Rodriguez-Abreu D, Bordoni A, Zucca E. Epidemiology of hematological malignancies. Ann Oncol. 2007:18(Suppl 1):i3-8.

7. Lichtman MA. Battling the hematological malignancies: the 200 years' war. Oncologist. 2008:13(2):126-38.

8. Hamid GA. The pattern of hematological malignancies at Al-Gamhouria teaching hospital, Aden, Yemen, from 2008 to 2010. Turk J Hematol. 2012; 29:342-7.

9. Smith A, Howell D, Patmore R, Jac A, Roman E. Incidence of haematological malignancy by sub-type: a report from the Haematological malignancy research network. Br J Cancer. 2011;105:1684-92.

10. Errahhali ME, Errahhali ME, Boulouiz R, Ouarzane M, Bellaoui M. Distribution and features of haematological malignancies in eastern Morocco: a retrospective multicenter study over 5 years. BMC Cancer. 2016:16:159.

11. Hossain MS, lqbal MS, Khan MA, Rabbani MG, Khatun H. Diagnosed hematological malignancies in Bangladesh - a retrospective analysis of over 5000 cases from 10 specialized hospitals. BMC Cancer. 2014;14:438.

12. Babatunde A, Amiwero C, Olatunji P, Durotoye I. Pattern of Haematological Malignancies in llorin, Nigeria: A Ten Year Review. Internet J Hematol. 2008;5(2)1-7.

13. Curado MP, Edwards B, Shin HR, et al., editors. Cancer Incidence in Five Continents, Vol. 9. Lyon: International Agency for Research on Cancer; 2007. p. 101.

14. Prajapati Z, Kokani MJ, Gonsai RN. Clinicoepidemiological profile of hematological malignancies in pediatric age group in Ahmedabad. Asian J Oncol. 2017;3:54-8.

15. Weldetsadik AT. Clinical characteristics of patients with hematological malignancies at Gondar university hospital. North West Ethiopia Ethiop Med J. 2013;51(1):25-31.

16. Das KV, Aboobacker CM, Mathew O. Clinical presentation of leukemias in children in South Kerala. Indian Pediatr. 1974;11:431-8.

17. Siddaiahgari SR, Awaghad MA, Latha MS. Clinical, immunophenotype and cytogenetic profi le of acute lymphoblastic leukemia in children at tertiary health care Centre in India. Muller J Med Sci Res. 2015;6:112-8.

18. Herzog CM, Dey S, Hablas A, Khaled HM, Seifeldin IA, Ramadan M, El-Hamzawy $\mathrm{H}$, Wilson ML, Soliman AS. Geographic distribution of hematopoietic cancers in the Nile delta of Egypt. Ann Oncol. 2012;23:2748-55.

19. Mashhadi MA, Zakeri Z, Abdollahinejad MJ. Cancer Incidence in South East of Iran: Results of a Population-Based Cancer Registry. Shiraz E-Medical Journal. 2010;11(3)145-55. 